REVISTA DE DERECHO UNED, NÚM. 21, 2017

\title{
¿CIUDADANOS, SOPLONES Y PRÍNCIPES CLEMENTES EN UNA SOCIEDAD DEMOCRÁTICA?
}

\author{
CITIZENS, WHISTLE-BLOWERS AND LENIENT PRINCES \\ IN A DEMOCRATIC SOCIETY?
}

\author{
Premio de Artículos Jurídicos García Goyena \\ XVI Edición \\ Segundo premio
}

\section{DAVID ORdóÑEz Solís}

\begin{abstract}
"Por eso muchas conjuras son puestas al descubierto y aplastadas en sus inicios, y cuando una, en la que participan muchos hombres, se mantiene secreta por largo tiempo se considera un milagro", N. MAQUIAVELO, Discursos sobre la primera década de Tito Livio, III, 6, pág. 325 [1513-1515].
\end{abstract}

Resumen: La denuncia de ilegalidades o whistle-blowing está siendo utilizada por las sociedades democráticas para mejorar la eficacia de determinadas políticas públicas. No obstante, cultural y jurídicamente esta actuación supone serios problemas hasta el punto de que su traducción del inglés no es fácil a la mayoría de idiomas, como ocurre con el español. Desde no hace mucho tiempo el legislador y los jueces de los países más desarrollados de la OCDE están elaborando un estatuto jurídico del whistle-blower, que lo proteja frente a eventuales represalias, por ejemplo en su entorno laboral. Asimismo, la política de clemencia frente a los infractores que denuncian a otros ofrece una perspectiva en este ámbito y se está aplicando de manera significativa en el derecho de la competencia y en la regulación de los mercados financieros. En España, a pesar de los escándalos por la corrupción, la introducción de estos procedimientos se hace de manera muy tímida y solo ha logrado calar a través de la recepción del derecho de la Unión Europea y mediante alguna reforma del procedimiento administrativo.

Palabras clave: derecho de la competencia, mercado financiero, política de clemencia, política pública, whistle-blower. 
Abstract: Whistle-blowing is a procedure used in democratic societies in order to improve the effectiveness of some specific public policies. However, culturally and legally this action raises problems, notably its translation in so far as there are no neutral equivalents of this English term into most of the languages, i.e. Spanish. Recently, law-makers and judges in the most OEDC developed countries are establishing new rules that protect whistle-blowers' activity from reprisals, notably at work. Moreover, leniency policy regarding infringers has been developed properly in competition law and in financial services rules. In Spain, although the scandals due to the corruption, these legal remedies have been scarcely introduced through the implementation of the European Union's law and by the recent legislative reform on administrative procedure.

Keywords: competition law, financial market, leniency policy, public policy, whistle-blower.

Sumario: 1. Introducción; 2. La denuncia de ilegalidades y la elaboración de un concepto neutro de whistle-blower; 2.1 El término whistle-blower $y$ sus traducciones a otros idiomas (y culturas); $2.2 \mathrm{La}$ configuración jurídica del whistle-blowing y su recepción en Europa; 3. Las garantías frente a las represalias de quienes denuncian ilegalidades en una sociedad democrática; 3.1 Los derechos fundamentales como garantía de los whistle-blowers en la jurisprudencia del Tribunal Europeo de Derechos Humanos; 3.2 Los desarrollos normativos en la Unión Europea: el Reglamento de abuso de mercado y la protección de los intereses financieros; 3.3 La nueva regulación autonómica española de protección de los informantes; 4 . La clemencia en el ejercicio de la potestad sancionadora para quienes denuncian ilegalidades; $4.1 \mathrm{La}$ política de clemencia en el Derecho europeo de la competencia y su aplicación en España; 4.1.1 La política de clemencia de la Comisión Europea y su control por los tribunales europeos; 4.1.2 La política de clemencia y la reparación de los daños causados por las prácticas antitrust: jurisprudencia Pfleiderer; 4.1.3 La política de clemencia de las autoridades administrativas españolas de la competencia; $4.2 \mathrm{La}$ generalización de la política de clemencia en el Derecho administrativo sancionador español; 5. Los incentivos económicos para denunciar ilegalidades; 6. Conclusión.

\section{INTRODUCCIÓN}

La traición y la delación son dos acciones especialmente reprobables y condenables en nuestra cultura en la medida en que afectan a 
valores tan esenciales de una comunidad y de un grupo como la confianza recíproca. No obstante, la valoración de estos actos depende en gran medida de la perspectiva. Así, en los procesos revolucionarios que triunfan, los traidores se convierten ipso facto e ipso iure en héroes y padres de la patria. Y en otros ámbitos tan distintos como la infancia o el hampa suelen crearse inevitablemente unas relaciones de fidelidad y confianza dentro del grupo cuyo quebrantamiento supone muy a menudo la muerte figurada o real de quien ose romper estas reglas esenciales. En realidad, en el lenguaje ordinario son numerosos los términos utilizados para referirse a estas circunstancias y por lo general tienen una indudable carga peyorativa como así ocurre con acusica, chivato o soplón.

Por razones bien distintas, en las sociedades democráticas y en determinados ámbitos de la intervención pública, como el control de la libre competencia, de los mercados financieros o simplemente del gasto, se puede observar la importancia que tiene la denuncia de los ciudadanos para atajar las ilegalidades hasta el punto de adoptarse leyes que propician y amparan a los denunciantes, como es el caso paradigmático de la Whistleblower Protectión Act estadounidense de $1989^{1}$. No obstante, el riesgo de los denunciantes es muy alto porque quedan expuestos a represalias de todo tipo. Esto ha propiciado que se establezcan garantías de los denunciantes o incluso se incentiva la denuncia de ilegalidades con la promesa de recompensas públicas; o, en fin, a quien denuncie ilegalidades en las que haya participado se le beneficia con la clemencia en el correspondiente procedimiento sancionador hasta el punto de asegurarle la exención total o parcial de las sanciones que merecería ${ }^{2}$.

El poder, quien quiera que lo ejerza, siempre ha utilizado la vía de la denuncia o la delación para controlar todo intento de subversión hasta el punto de reconocer beneficios para quien denuncie o delate un crimen en el que haya participado siempre que, de este modo, se pueda haber atajado tal mal y se haya podido castigar a los infractores.

En las sociedades totalitarias, como ha ocurrido en particular durante el siglo Xx, en los países comunistas, por ejemplo y de manera

${ }^{1}$ An Act to amend title 5, United States Code, to strengthen the protections available to Federal employees against prohibited personnel practices, and for other purposes, 103 STAT. 16 PUBLIC LAW 101-12-APR. 10, 1989.

${ }^{2}$ Lewis, David, y Wim VANDEKercKhove (ed.) (2011): Whistleblowing and Democratic Values, The International Whistleblowing Research Network, disponible en http://whistleblowers.dk/ArkivPDF/whistleblowing_and_democratic_values_3rd_ jan(1).pdf (consulta: 10/01/2017). 
muy notable, los antiguos países socialistas del Centro y Este de Europa, el Estado se construyó a partir de la delación y del espionaje de unos ciudadanos sobre otros. Los métodos de la Stasi en la República Democrática Alemana hasta la caída del Muro de Berlín en 1989 deben ser una advertencia permanente.

En cambio, en las sociedades democráticas se ha propiciado la denuncia de irregularidades e ilegalidades a través de una figura con una denominación acuñada en inglés, whistle-blower, y que en otros idiomas sigue buscando su identificación, que pretende tener connotaciones positivas hasta el punto de que se ha llegado a garantizar determinadas denuncias de ilegalidades en el ámbito público o privado, se ha construido una política de clemencia (leniency policy) por parte de los poderes sancionadores o, de manera más simple, se ha incentivado económicamente la denuncia de irregularidades e ilegalidades.

Aparte de nuestra torturada historia vinculada a la Inquisición, la reciente Guerra civil y la ominosa dictadura franquista, es difícil saber por qué en la España apenas ha tenido relevancia, ni siquiera en el debate público, la cuestión de las denuncias. Desde fuera se ha apuntado, quizás de manera simplificada, la necesidad de adoptar soluciones al estilo anglosajón, aunque todo parece indicar que el whistleblowing es una causa perdida en nuestro país ${ }^{3}$. No obstante, estas nuevas corrientes se han canalizado a través del Derecho de la Unión Europea, primero en el ámbito del Derecho de la competencia, luego en materia de protección de datos personales, o incluso en el ámbito fiscal, y han terminado cristalizando en una norma general aplicable al procedimiento administrativo sancionador que parece anunciar una configuración especial de la política administrativa sancionadora.

Ahora bien, la incorporación de estas nuevas instituciones choca, no obstante, con tradiciones culturales especialmente arraigadas y que, por tanto, ofrecen aspectos de gran interés no solo desde el punto de vista jurídico sino también en la misma cultura cívica. Sobre este particular, la Asamblea parlamentaria del Consejo de Europa explicaba que era necesario introducir las necesarias mejoras legislativas acompañadas por una evolución positiva en la actitud cultural

${ }^{3}$ Minder, Raphael (2016): "Spanish Whistle-Blowers Seek Law Giving Refuge», The New York Times, 15 de mayo de 2016, pág. A6; el titular de la edición en Internet del día anterior era también significativo «Uncovering Corruption Is a Risky Endeavor in Spain». 
hacia el whistle-blowing, que debe liberarse de la asociación previa con la deslealtad y la traición ${ }^{4}$.

Con el presente estudio pretendo abordar los cambios institucionales y procedimentales que tienen un origen más profundo vinculado a los valores y a la cultura cívica. De hecho, trataré de identificar estos cambios judiciales y legislativos en el ámbito europeo y de qué modo se están aplicando o se pueden adoptar en España.

En una primera parte, me refiero a la búsqueda de un concepto neutro de denunciante de ilegalidades o whistle-blower y detallo, brevemente, su evolución en el Derecho de la Unión. En la segunda parte, expongo el modo en que se está intentando construir, es verdad que de manera fragmentaria, tanto legislativa como jurisprudencialmente, un estatuto del denunciante de irregularidades. En la tercera parte, analizo algunas experiencias sectoriales de la política de clemencia de los denunciantes que hayan participado en actos ilegales. Por último, apunto los intentos de trasladar la experiencia estadounidense a la Unión Europea incentivando económicamente la denuncia de ilegalidades en ámbitos tan concretos como los mercados financieros o la gestión de fondos europeos.

\section{LA DENUNCIA DE ILEGALIDADES Y LA ELABORACIÓN DE UN CONCEPTO NEUTRO DE WHISTLE-BLOWER}

La denuncia de ilegalidades no tiene una delimitación fácil en el ámbito jurídico porque, precisamente, sus contornos éticos y políticos tampoco están suficientemente claros. De hecho, la falta de una denominación, aparte del término inglés whistle-blowing para la acción y whistle-blower para el sujeto que la emprende, revela precisamente la dificultad de conceptuarla ${ }^{5}$.

Asimismo, se están elaborando algunos principios, fundamentalmente enunciados en instrumentos propios del soft-law de organizaciones internacionales con propósitos tan distintos como los mera-

${ }^{4}$ Asamblea Parlamentaria del Consejo de Europa (2010): Resolución 1729 (2010), de 9 de abril, de protección de los whistle-blowers; disponible en http://assembly.coe. int/nw/xml/XRef/Xref-XML2HTML-EN.asp?fileid=17851\&lang=en (última consulta: 10/01/2017).

${ }^{5}$ BANISAR, David (2011): «Whistleblowing: International Standards and Developments», en Sandoval, I. (editor), Corruption and Transparency: Debating the Frontiers between State, Market and Society, World Bank-Institute for Social Research, UNAM, Washington, D. C.; disponible en http://papers.ssrn.com/sol3/papers.cfm?abstract_ $\mathrm{id}=1753180$ (consulta: 10/017/2017). 
mente económicos (Organización para la Cooperación y el Desarrollo Económicos, OCDE, de París) o los de integración política y defensa de los derechos humanos (Consejo de Europa, de Estrasburgo).

\subsection{El término whistle-blower y sus traducciones a otros idiomas (y culturas)}

En español, como en otros idiomas, no existe consenso para traducir whistle-blower, sino que se opta por reproducir los términos ingleses whistle-blower para referirse a quien denuncia irregularidades o ilegalidades o whistle-blowing para aludir a la propia acción de denuncia o bien se recurre a términos o expresiones equivalentes.

El término whistle-blower se recogió por primera vez en la edición de 1986 del Oxford Dictionary of English ${ }^{6}$. Su definición es la siguiente: "A person who informs on a person or organization regarded as engaging in an unlawful or immoral activity» [Una persona que informa sobre una determinada persona u organización que haya realizado una actividad ilícita o inmoral].

Las 45 entradas de whistleblower en la Wikipedia revelan las distintas estrategias seguidas para traducir la palabra inglesa en un sentido neutro en el respectivo idioma y que van desde el uso de la misma expresión inglesa, como ocurre en alemán o italiano; a sugerir términos anodinos como denunciante en portugués o un poco más extraños como alertador en español o revelador d'informació en catalán; o, en fin, acuñan un término inspirado en el símil inglés: lanceur d'alerte en francés o klokkenluider (campanero) en neerlandés ${ }^{7}$.

En el Diccionario del Español Jurídico de 2016 no se recoge el término inglés ni ninguna acepción que se acerque siquiera indirectamente al concepto de whistle-blower ${ }^{8}$. Es muy significativo que a finales de 2016 tres leyes autonómicas (castellano-leonesa ${ }^{9}$, valenciana ${ }^{10} \mathrm{y}$

${ }^{6}$ OECD (2016): Committing to Effective Whistleblower Protection, DOI:10.1787/9789264252639-en, OECD Publishing, París, pág. 23.

${ }^{7}$ Disponible en https://www.wikidata.org/wiki/Q26102\#sitelinks-wikipedia (consulta: 07/01/2017)

${ }^{8}$ Muñoz Machado, Santiago (dir.) (2016): Diccionario del español jurídico, Real Academia Española y Consejo General del Poder Judicial, Madrid.

${ }^{9}$ Ley 2/2016, de 11 de noviembre, por la que se regulan las actuaciones para dar curso a las informaciones que reciba la Administración Autonómica sobre hechos relacionados con delitos contra la Administración Pública y se establecen las garantías de los informantes (BOE núm. 296, de 8 de diciembre de 2016).

${ }^{10}$ Ley 11/2016, de 28 de noviembre, de la Agencia de Prevención y Lucha contra el Fraude y la Corrupción de la Comunitat Valenciana (BOE núm. 306, de 20/12/2016). 
balear $^{11}$ ) que abordan esta cuestión evitan el término inglés y, en cambio, parecen optar por utilizar el término informante.

El legislador de la Unión Europea se ha tenido que enfrentar a la traducción en los 23 idiomas oficiales, de un texto como el Reglamento sobre abuso de mercado, aplicable a los mercados financieros ${ }^{12}$. Sin embargo, la solución no parece satisfactoria: en inglés el término utilizado fue el de whistleblower, en español el de confidente, en francés el de informateur; el de Informant en alemán; autore della segnalazione en italiano; en neerlandés, Klokkenluider; y en portugués: as pessoas com acesso a informação interna.

Del mismo modo, la acción de whistleblowing schemes se traduce en español como 'programas de incentivos establecidos para los confidentes'; en francés, 'systèmes de dénonciation'; en alemán, Informanten Mechanismen; en italiano 'i sistemi di segnalazione di abusi', en neerlandés: klokkenluidersregelingen; y en portugués os mecanismos de denúncia por pessoas com acesso a informação interna.

En la Directiva (UE) 2016/943 sobre secretos comerciales también se sigue la misma estrategia de traducción de forma que whistleblowing activity se convierte en la denuncia de irregularidades, les activités des lanceurs d'alertes, Whistleblowing-Aktivitäten o, en fin, denúncia de irregularidades ${ }^{13}$.

\subsection{La configuración jurídica del whistle-blowing y su recepción en Europa}

En la OCDE se observa la adopción en los últimos veinte años de una legislación comparada muy variada. Por ejemplo, en una encuesta de 2014 se comprobó que 18 de 32 Estados de la OCDE tenían una legislación específica en materia de whistleblowing; sin embargo, ha-

${ }^{11}$ Ley 16/2016, de 9 de diciembre, de creación de la Oficina de Prevención y Lucha contra la Corrupción en las Illes Balears (BOE núm. 8, de 10 de enero de 2017).

${ }_{12}$ Reglamento (UE) núm. 596/2014 del Parlamento Europeo y del Consejo, de 16 de abril de 2014, sobre el abuso de mercado (Reglamento sobre abuso de mercado) y por el que se derogan la Directiva 2003/6/CE del Parlamento Europeo y del Consejo, y las Directivas 2003/124/CE, 2003/125/CE y 2004/72/CE de la Comisión (DOUE núm. L 173 de 12.6.2014, pág. 1).

${ }^{13}$ Directiva (UE) 2016/943 del Parlamento Europeo y del Consejo, de 8 de junio de 2016, relativa a la protección de los conocimientos técnicos y la información empresarial no divulgados (secretos comerciales) contra su obtención, utilización y revelación ilícitas (DOUE núm. L 157, 15.6.2016, pág. 1). 
bía países como España, Suecia, Polonia, Finlandia o la República Checa que no tenían regulación alguna ${ }^{14}$.

El punto de partida en la OCDE fue la adopción de los principios para la aplicación de la ética a los servicios públicos (OECD Principles for Managing Ethics in the Public Service) que pretenden crear un estatuto del empleado público que conozca sus derechos y obligaciones a la hora de denunciar las irregularidades ${ }^{15}$.

En el Consejo de Europa se han articulado algunas iniciativas y se han enunciado los principios relativos a la denuncia de ilegalidades a través de la Resolución de la Asamblea Parlamentaria de 2010 y de la Resolución del Comité de Ministros de 2014.

En 2010, la Asamblea Parlamentaria estableció unos principios legislativos que determinan el ámbito de aplicación y fijan algunos elementos estructurales. Por una parte, la Resolución pretende que la legislación se refiera a todo tipo de denuncias respecto de actos ilegales, que incluyan todas las violaciones serias de los derechos humanos que afecten o amenacen la vida, la salud, la libertad y cualquier otro interés legítimo de los particulares en calidad de administrados o de contribuyentes de una administración pública, pero también accionistas, empleados o clientes de empresas privadas; que abarque el ámbito público y privado, incluidas las fuerzas armadas; y, en fin, propugna que se codifiquen los desarrollos normativos en materia de derecho laboral, derecho penal y procesal, derecho de las comunicaciones, en especial para proteger las fuentes de los periodistas, y las medidas específicas contra la corrupción. Por otra parte, se proponen algunas ideas básicas de la legislación con el fin de establecer una alternativa segura al silencio, de manera que se ampare a quien actúe de buena fe, que se establezcan canales internos, que se proteja frente a las represalias y también contra las acusaciones falsas.

En 2014 el Comité de Ministros definió el whistleblower o el lanceur d'alerte como cualquier persona que informa o revela informaciones relativas a las amenazas o a un perjuicio para el interés general en

${ }^{14}$ OECD (2016): Committing to Effective Whistleblower Protection, ob. cit., pág. 23.

${ }^{15}$ CONSEJO DE LA OCDE (1998): Recommendation on Improving Ethical Conduct in the Public Service, Including Principles for Managing Ethics in the Public Service, París. 
el contexto de su relación de trabajo tanto en el sector público como en el sector privado ${ }^{16}$.

En 2016 se hizo pública una iniciativa parlamentaria que se había concretado en un Borrador de Directiva presentada por el Grupo de Los Verdes del Parlamento Europeo ${ }^{17}$.

La base jurídica de este Borrador de Directiva es la política social. Subsidiariamente se invoca la realización del mercado interior y la lucha contra la corrupción. Con la Directiva se pretende, en particular, establecer procedimientos efectivos que garanticen a los empleados públicos y privados frente a cualquier represalia por haber revelado información obtenida con ocasión de su relación laboral y en la medida en que afecte o dañe el interés público.

También en 2016 se presentó en el mundo académico una Propuesta de Directiva del Parlamento y del Consejo por el que se establece un nivel mínimo de protección de los whistleblowers (Proposition pour une directive établissant un standard minimum de protection des lanceurs d'alerte) $)^{18}$.

En los anteriores documentos se observa la necesidad no solo de encontrar el término equivalente al de whistle-blower sino también definir el objeto de la acción de whistle-blowing. A tal efecto, sería preciso definir desde un punto de vista jurídico el objeto de la denuncia, lo que abreviadamente denomino ilegalidad, debiendo quedar fuera otros ámbitos como el de la ética.

De acuerdo con la legislación estadounidense, la Whistleblower Protection Act de 1989, el objeto de la divulgación sería, por una parte, la violación de cualquier ley, norma o regulación (A: violation of any law, rule, or regulation) y, por otra parte, la mala administración grave, la malversación grave de fondos, el abuso de autoridad o la amenaza

${ }^{16}$ Comité de Ministros del Consejo de Europa (2014): Recommendation CM/Rec (2014) 7 adopted on 30 April 2014 and explanatory memorandum; Recommandation $\mathrm{CM} / \operatorname{Rec}$ (2014) 7 sur la protection des lanceurs d'alerte; disponible en https://www. coe.int/t/dghl/standardsetting/cdcj/CDCJ\%20Recommendations/CMRec(2014)7E.pdf (consulta: 10/01/2017).

${ }^{17}$ The Greens / European Free Alliance (2016): Whistleblower Protection in the Public and Private Sector in the European Union. A Draft Directive, Parlamento Europeo, 4 de mayo de 2016, disponible en http://www.greens-efa.eu/legacy/fileadmin/ dam/Images/Transparency_campaign/WB_directive_draft_for_consultation_launch_ May_2016.pdf (consulta: 07/01/2017).

18 JUNGERS, Marine (2016): Le lanceur d'alerte au regard des droits fondamentaux: vers un nouveau statut européen?, Faculté de droit et de criminologie, Université catholique de Louvain, Prom.: Olivier De Schutter; disponible en: http://hdl.handle. net/2078.1/thesis:7989, págs. 78-93 (consulta: 10/01/2017). 
sustancial y específica a la salud pública o a la seguridad (B: gross mismanagement, a gross waste of funds, an abuse of authority, or a substantial and specific danger to public health or safety).

En el Derecho de la Unión Europea se puede apreciar que en el concepto de ilegalidad se incluye por lo general toda acción que no sea conforme a Derecho, incluso las irregularidades financieras. En efecto, el Tribunal de Justicia en su sentencia Wroctaw ofrece la siguiente definición de irregularidad: «toda infracción de una disposición del Derecho de la Unión correspondiente a una actuación u omisión de un agente económico y que tenga, o que pueda tener, por consecuencia causar un perjuicio al presupuesto general de la Unión al cargarle un gasto injustificado» ${ }^{19}$.

\section{LAS GARANTÍAS FRENTE A LAS REPRESALIAS DE QUIENES DENUNCIAN ILEGALIDADES EN UNA SOCIEDAD DEMOCRÁTICA}

El estatuto del denunciante de ilegalidades tiene como objetivo claro evitar las represalias que, sin lugar a dudas, desincentivan cualquier intento de contribuir al bien común. La importancia de estas garantías ha sido destacada desde un enfoque politológico que considera la transparencia una cualidad constitutiva de un gobierno democrático y que se refiere, precisamente, a sus tres dimensiones: la apertura del gobierno, la protección de los whistleblowers y la publi$\operatorname{cidad}^{20}$.

En Europa hasta el momento no existe un tratamiento jurídico sistemático de las garantías sino que, fragmentariamente, en el ámbito judicial y legislativo se han ido haciendo aportaciones en los últimos diez años. Por una parte, el Tribunal Europeo de Derechos Humanos ha desarrollado en su jurisprudencia algunos aspectos relevantes de la garantía de los denunciantes derivada de los derechos fundamentales. Por otra parte, alguna legislación de la Unión

19 TJUE, sentencia de 14 de julio de 2016, Wrocław (Breslavia), C-406/14, EU: C:2016:562, apartado 41 (contratación pública y corrección financiera de los fondos europeos); véase el mismo enfoque en la sentencia de 3 de septiembre de 2014, Baltlanta, C-410/13, EU: C:2014:2157 (ejecución de la decisión relativa a la concesión de la ayuda al término del procedimiento judicial).

${ }^{20}$ BAUHR, Monika, y Marcia GRIMES (2012): What Is Government Transparency? New Measures and Relevance for Quality of Government, Working Paper Series 2012:16, The Quality of Government Institute, University of Gothenburg; disponible en http://qog.pol.gu.se/digitalAssets/1418/1418047_2012_16_bauhr_grimes.pdf (consulta: 07/01/2017). 
Europea ha abordado estas cuestiones de manera directa, en particular a través del Reglamento sobre abuso en los mercados financieros. Por último, las primeras legislaciones españolas provienen de los parlamentos autonómicos y parecen responder a una preocupante atención de las autoridades españolas, inmersas en numerosos escándalos de corrupción.

\subsection{Los derechos fundamentales como garantía de los whistle- blowers en la jurisprudencia del Tribunal Europeo de Derechos Humanos}

El Tribunal de Estrasburgo ha elaborado desde 2008 una interesantísima jurisprudencia sobre la denuncia de ilegalidades y el amparo de la libertad de expresión tanto de los empleados públicos como de los empleados privados.

La sentencia Guja c. Moldavia (2008) aborda la cuestión de la destitución del director de los servicios de prensa del Ministerio Fiscal en Moldavia como consecuencia de la publicación de dos cartas en un periódico de Chisinau donde se ponía de manifiesto el tráfico de influencias del vicepresidente del Parlamento nacional en relación con actuaciones penales previas. La impugnación de su destitución ante los tribunales moldavos fue sistemáticamente rechazada por lo que Iacob Guja acudió a Estrasburgo ${ }^{21}$.

El Tribunal Europeo se refiere a la protección que confiere la Convención de las Naciones Unidas contra la corrupción y las Convenciones penal y civil del Consejo de Europa sobre la corrupción a las personas que comunican informaciones. Y a continuación interpreta el derecho a la libertad de expresión de los empleados públicos.

En primer lugar, el Tribunal Europeo subraya la obligación de lealtad, reserva y discreción tanto de los funcionarios públicos como de los empleados privados. Precisamente, respecto de los funcionarios el Tribunal de Estrasburgo proclama: «la misión de los funcionarios en una sociedad democrática es la de ayudar al gobierno a cumplir sus funciones por lo que el público tiene derecho a confiar que los funcionarios aporten esta ayuda y no pongan obstáculos a un gobierno elegido democráticamente, por lo que la obligación de lealtad y

${ }^{21}$ TEDH (GC) sentencia de 12 de febrero de 2008, Guja c. Moldavia (recurso núm. 14277/04) (destitución del director de los servicios de prensa del Ministerio Fiscal moldavo por la publicación de dos cartas críticas con la intromisión del vicepresidente del Parlamento). 
reserva reviste para ellos una importancia particular [...] Además y dada la naturaleza de su posición, con frecuencia los funcionarios tienen acceso a informaciones respecto de las cuales el gobierno puede tener, por diversas razones legítimas, interés en proteger la confidencialidad o su carácter secreto. En cuyo caso, los funcionarios están obligados a una discreción muy estricta» (§ 71).

Ahora bien, el Tribunal Europeo, a la luz de la Convención civil europea sobre la corrupción, advierte sobre las dificultades para detectar e investigar los asuntos de corrupción por lo que los empleados y colegas del sector público o privado de las personas implicadas a menudo son los primeros en descubrir o en sospechar cualquier anomalía (§ 72).

Esto justifica, en primer lugar, una divulgación interna, es decir, ante el superior o ante una autoridad o instancia competente, de modo que la divulgación al público no puede considerarse más que el último recurso en caso de imposibilidad manifiesta de actuar de otra manera (§ 77).

En segundo lugar, para determinar la procedencia de la divulgación interna o externa el Tribunal Europeo aplica el principio de proporcionalidad. Y para ello tiene en cuenta el interés público de la información divulgada, su autenticidad, el daño que pueda causar al interés público, la buena fe del denunciante y la severidad de la sanción que se le haya impuesto.

El Tribunal considera, de manera decisiva, la motivación del denunciante y a tal efecto exige que el denunciante actúe de buena fe y pone este ejemplo: «un acto motivado por una queja o por una animadversión personales o incluso con la perspectiva de una ventaja personal, en particular una ganancia pecuniaria, no justifica un nivel de protección particularmente elevado» (§ 73).

En suma, el examen de estos presupuestos le permite al Tribunal Europeo concluir que hubo violación del derecho a la libertad de expresión al estar en juego cuestiones de interés general, el derecho de los funcionarios y de otros empleados de denunciar conductas o actos ilícitos constatados en su lugar de trabajo, sin perjuicio de los deberes y las responsabilidades de los empleados respecto de sus empleadores y del derecho de estos a gestionar su personal (§ 97).

La sentencia Heinisch c. Alemania (2011) también resuelve la cuestión de la libertad de expresión en el lugar de trabajo, en este caso una enfermera de un geriátrico público que había denunciado graves 
carencias en materia de personal ${ }^{22}$. Al haber recurrido sin éxito a los tribunales alemanes, incluido el Tribunal Constitucional, Brigitte Heinisch acudió a Estrasburgo.

En este caso el Tribunal Europeo tiene en cuenta, en particular, la Resolución 1729 (2010) relativa a la protección de los whistle-blowers de la Asamblea Parlamentaria del Consejo de Europa y el artículo 24 de la Carta Social Europea revisada conforme al cual los trabajadores tienen derecho a no ser despedidos sin motivo válido vinculado a su aptitud o conducta o fundado sobre las necesidades de funcionamiento de la empresa. El Tribunal Europeo precisa que no constituye motivo de despido haber presentado una queja o haber participado en procedimientos seguidos contra un empleador en razón de violaciones invocadas de la legislación, o haber presentado un recurso ante las autoridades administrativas competentes ${ }^{23}$.

En esta sentencia el Tribunal Europeo expone y examina los presupuestos establecidos en la sentencia Guja c. Moldavia y enjuicia el interés público de la información divulgada, si la recurrente tenía canales alternativos para divulgar la información, sobre la autenticidad de la información facilitada, si actuó con buena fe, cuál fue el perjuicio causado al empleador y cuál había sido la severidad de la sanción. La enfermera había intentado en varias ocasiones denunciar la situación ante sus superiores pero finalmente no tuvo otro remedio que acudir a una vía externa de denuncia, en este caso presentó una querella criminal.

${ }^{22}$ TEDH, sentencia de 21 de julio de 2011, Heinish c. Alemania (recurso núm. 28274/08) (despido de una enfermera de un geriátrico del Land de Berlín por haber denunciado graves carencias por falta de personal).

${ }^{23}$ El Tribunal Constitucional español ha elaborado una copiosa jurisprudencia sobre la denominada "garantía de indemnidad» que se traduce en la imposibilidad de adoptar medidas intencionales de represalia derivadas del ejercicio por el trabajador de la tutela de sus derechos; véase, por ejemplo, la sentencia del Pleno 183/2015, de 10 de septiembre (ponente: Valdés Dal-Ré) donde señala: «la vulneración del derecho a la tutela judicial efectiva no sólo se produce por irregularidades acaecidas dentro del proceso judicial que ocasionen privación de garantías procesales, sino que, asimismo, tal derecho puede verse también lesionado cuando su ejercicio, o la realización por el trabajador de actos preparatorios o previos necesarios para una acción judicial, produzca como consecuencia una represalia empresarial o, en todo caso, un efecto negativo en su posición y patrimonio de derechos. En suma, el derecho consagrado en el art. 24.1 CE no sólo se satisface mediante la actuación de los Jueces y Tribunales, sino también a través de la garantía de indemnidad, lo cual significa que del ejercicio de una acción judicial -individual o colectiva [...]- o de los actos preparatorios o previos al mismo -incluso de reclamaciones extrajudiciales dirigidas a evitar el proceso [...]- no pueden seguirse consecuencias perjudiciales en el ámbito de las relaciones públicas o privadas para la persona que los protagoniza» (FJ 3). 
El Tribunal de Estrasburgo constató que la enfermera había sido movida a actuar con el fin de mejorar sus condiciones de trabajo y no duda de que actuó de buena fe en favor del interés general, denunciando un comportamiento ilícito del empleador. En fin, el Tribunal Europeo subraya que el Derecho alemán no proporcionó un específico mecanismo de aplicación para investigar la queja de un denunciante y para aplicar medidas correctoras contra el empleador (§ 75).

La sentencia Bucur y Toma c. Rumanía (2013) aborda la cuestión de la divulgación de secretos militares ${ }^{24}$. El Tribunal Europeo se refiere expresamente a la Resolución 1729 (2010) de la Asamblea Parlamentaria, a los trabajos del grupo GRECO (Grupo de Estados contra la Corrupción) del Consejo de Europa sobre la divulgación de informaciones confidenciales y, en fin, a la jurisprudencia Guja c. Moldavia.

A la hora de aplicar los distintos presupuestos, el Tribunal Europeo examina si había medios alternativos a la divulgación y comprueba que en ese momento, en la legislación rumana en general y en la relativa a los servicios de información en particular, no había disposiciones que permitiesen la divulgación por los empleados de irregularidades cometidas en el lugar de trabajo (§ 96).

A raíz de este caso, se adoptó la Ley rumana núm. 571/2004 que protege a los whistle-blowers en el ámbito de la función pública, saludada positivamente por el propio Tribunal Europeo junto con las legislaciones de Noruega, Estados Unidos y Reino Unido ( $\S 999$ y 62).

En suma, el Tribunal Europeo comprueba que se cumplen los demás requisitos exigidos por la jurisprudencia por lo que concluye considerando que hubo una vulneración del derecho de libertad de expresión del militar recurrente.

En fin, la sentencia Matúz c. Hungría (2015) se refiere al despido de un periodista de la televisión pública húngara por denunciar en un libro la existencia de censura en su empresa ${ }^{25}$. Los recursos a los distintos tribunales húngaros no produjeron efecto y, finalmente, Gábor Matúz acudió al Tribunal de Estrasburgo.

${ }^{24}$ TEDH, sentencia de 8 de enero de 2013, Bucur y Toma c. Rumanía (recurso núm. 40238/02) (penas de prisión para militar por revelar secretos de registros de comunicaciones telefónicas).

${ }_{25}$ TEDH, sentencia de 21 de octubre de 2015, Matúz c. Hungría (recurso núm. 73571/10) (despido de un periodista de televisión por revelar datos confidenciales de su empresa). 
Después de recordar su jurisprudencia, en particular la sentencia Fuentes Bobo c. España (2000) ${ }^{26}$, el Tribunal Europeo considera que la obligación de discreción y de confidencialidad no pueden aplicarse con igual fuerza a los periodistas, dada la naturaleza de su función de informar y de aportar ideas (§ 39).

Finalmente, el Tribunal Europeo, al aplicar el derecho a la libertad de expresión, tiene en cuenta, por una parte, las obligaciones y responsabilidades del periodista, y, por otra parte, los deberes y responsabilidades de los empleados hacia sus empleadores. Ponderados todos los intereses en juego, concluyó el Tribunal de Estrasburgo que la interferencia en la libertad de expresión del Sr. Matúz no había sido necesaria en una sociedad democrática.

\subsection{Los desarrollos normativos en la Unión Europea: el Reglamento de abuso de mercado y la protección de los intereses financieros}

En el ámbito de los mercados financieros, el Reglamento (UE) núm. 596/2014 sobre abuso de mercado introduce en la legislación europea la figura del confidente, la traducción oficial elegida por la versión española, del whistleblower.

En el preámbulo del Reglamento sobre abuso de mercado se recoge una confesión suficientemente expresiva de lo que significa el whistle-blower y de los términos en que se acoge en la legislación europea:

Los confidentes proporcionan a las autoridades competentes nueva información que permite detectar y sancionar los casos de operaciones con información privilegiada y de manipulación de mercado. No obstante, pueden verse disuadidos de ello por miedo a las represalias o por falta de incentivos. La comunicación de las infracciones del presente Reglamento es necesaria para que las autoridades competentes puedan detectar y sancionar los abusos de mercado. Son necesarias medidas sobre los confidentes para facilitar la detección de los abusos de mercado y asegurar la protección y el respeto de los derechos de los confidentes y de los acusados. Por tanto, el presente Reglamento debe garantizar la implantación de mecanismos adecuados para que los confidentes puedan alertar a las autoridades competentes acerca de posibles infracciones y protegerles de represalias (apartado 74).

${ }^{26}$ TEDH, sentencia de 29 de febrero de 2000, Fuentes Bobo c. España (recurso núm. 39293/98) (violación de la libertad de expresión de un periodista por ser desproporcionado su despido de TVE por críticas vertidas en la radio contra los dirigentes de la televisión pública). 
Ya en la parte dispositiva del Reglamento sobre abuso de mercado se refiere en su artículo 32 a la Comunicación de las infracciones.

En primer lugar, el Reglamento prevé el establecimiento de canales eficaces y seguros para permitir la comunicación de las infracciones. Estos canales deben ser tanto externos, ante los organismos públicos de los mercados financieros, como internos, ante el propio empleador.

En segundo lugar, el Reglamento europeo exige una protección adecuada de la relación laboral de quien denuncie. Se trata de la garantía frente a represalias, discriminación u otros tipos de trato injusto.

En tercer lugar, el Reglamento se refiere a la protección de los datos de quien denuncie la infracción, preservando la confidencialidad de su identidad, con el único límite de las investigaciones o procedimientos judiciales posteriores ${ }^{27}$.

En cuarto lugar, el Reglamento establece los principios básicos de la concesión de incentivos económicos a quienes denuncien ilegalidades en este ámbito.

Por último, se prevé la intervención de la Comisión Europea para establecer los procedimientos de comunicación de infracciones y su seguimiento.

Se trata de una legislación que, en lo referido a la comunicación de infracciones, tenía que haber sido incorporada a las legislaciones nacionales de los 28 Estados miembros antes del 3 de julio de 2016. Es previsible que la intervención prejudicial del Tribunal de Justicia aporte una interpretación uniforme en toda la Unión Europea.

En lo que se refiere a la protección de los intereses financieros de la Unión Europea, es preciso recordar el importante esfuerzo que las instituciones han hecho desde 1999 para luchar contra la corrupción, especialmente a partir de la creación de la Oficina Europea de Lucha contra el Fraude (OLAF).

Las reformas legislativas han permitido establecer canales y garantías contra los denunciantes de ilegalidades en el seno de las insti-

${ }^{27}$ Sobre la perspectiva de la protección de datos y las relaciones entre el sistema estadounidense y europeo, véase, el dictamen del GRUPO DE TRABAJO DEL ARTículo 29 (2006): Opinion 1/2006 on the application of EU data protection rules to internal whistleblowing schemes in the fields of accounting, internal accounting controls, auditing matters, fight against bribery, banking and financial crime, Bruselas, 1 de febrero de 2006, 00195/06/EN, WP 117; disponible en http://ec.europa.eu/justice/data-protection/ article-29/documentation/opinion-recommendation/index_en.htm (consulta: 11/01/2017). 
tuciones europeas; de hecho, se establecen escalonadamente tres opciones de comunicación: primera opción de internal whistleblowing (ante el Jefe de Unidad o el Director General); segunda opción de internal whistleblowing (ante la OLAF); y tercera opción de external whistleblowing (ante el Defensor del Pueblo, el Consejo, el Parlamento Europeo, etc. $)^{28}$.

\subsection{La nueva regulación autonómica española de protección de los informantes}

La atención a quienes denuncian ilegalidades había sido nula en el Derecho español hasta que casi al mismo tiempo a finales de 2016 tres leyes autonómicas adoptan innovaciones especialmente significativas.

Estas tres leyes autonómicas ya citadas son: la Ley castellano-leonesa 2/2016 por la que se regulan las actuaciones para dar curso a las informaciones que reciba la Administración Autonómica sobre hechos relacionados con delitos contra la Administración Pública y se establecen las garantías de los informantes; la Ley valenciana 11/2016 de la Agencia de Prevención y Lucha contra el Fraude y la Corrupción; y la Ley balear 16/2016 de la Oficina de Prevención y Lucha contra la Corrupción.

La Ley castellano-leonesa pretende proteger a los informantes. Así lo indica no solo el título de la ley sino también su preámbulo: «El reconocimiento de la importancia de estas informaciones suele ir acompañado de la adopción de medidas legales que, por un lado, incrementen la confianza en los procedimientos mediante los que se tramiten las informaciones que pudieran facilitarse y, por otro, garanticen la protección de los informantes frente a posibles acciones que pudieran perjudicar su situación laboral».

La Ley castellano-leonesa procura establecer las garantías tal como resulta del artículo 3.1 conforme al cual: «Frente a quien haya facilitado la información no podrá adoptarse ninguna medida que venga motivada por tal actuación y que perjudique su relación de servicio o condiciones de trabajo. De forma particular, no podrá ser removido de su puesto de trabajo, cualquiera que sea su forma de pro-

\footnotetext{
${ }^{28}$ Comisión Europea (2012): Communication from Vice-President Šefčovič to the Commission on Guidelines on Whistleblowing, Brussels, 6.12.2012, SEC (2012) 679 final.
} 
visión, salvo aquellos cambios que se deriven estrictamente de la normativa aplicable».

La ley valenciana tiene como objetivo establecer una Agencia de Prevención y Lucha contra el Fraude y la Corrupción pero, al mismo tiempo, elabora un interesante estatuto de la persona denunciante. A tal efecto, en el artículo 14 se refiere al estatuto y a la oficina virtual del empleado público, una verdadera oficina valenciana del whistle-blower, a imagen de la Oficina del whistleblower de la SEC estadounidense.

Los elementos básicos del estatuto de la persona denunciante en la Comunidad Valenciana son el concepto de denunciante, las denuncias falsas, los procedimientos de denuncia y los derechos y garantías del denunciante.

En cuanto al propio concepto de denunciante, se somete precisamente a la protección de la Agencia y «se considera persona denunciante cualquier persona física o jurídica que comunique hechos que pueden dar lugar a la exigencia de responsabilidades legales».

También prevé que la Agencia establezca los procedimientos de denuncia y adelanta sus características: procedimientos y canales confidenciales que garanticen la estricta confidencialidad cuando así lo invoque el denunciante. Estos procedimientos y canales podrán ser utilizados para comunicar represalias $\mathrm{u}$ otras actuaciones lesivas derivadas de la presentación de la denuncia.

Sobre los derechos y garantías del denunciante, es la Agencia valenciana la que tiene encomendada la protección de los denunciantes, quien debe asesorar legalmente a los denunciantes de buena fe y debe garantizarles la confidencialidad de su identidad. La Agencia valenciana también actúa como garantía frente a las represalias, de modo que "velará para que estas personas no sufran, durante la investigación ni después de ella, ningún tipo de aislamiento, persecución o empeoramiento de las condiciones laborales o profesionales, ni ningún tipo de medida que implique cualquier forma de perjuicio o discriminación». También se atribuye a la Agencia valenciana la potestad de ejercer acciones correctoras o de restablecimiento, lo que puede incluir poder «instar al órgano competente a trasladarla a otro puesto, siempre que no implique perjuicio a su estatuto personal y carrera profesional y, excepcionalmente, podrá también instar al órgano competente a conceder permiso por un tiempo determinado con mantenimiento de la retribución». Asimismo, el denunciante podrá solicitar asesoramiento en los procedimientos que se interponen contra él con motivo de la denuncia. 
En fin, respecto de las denuncias falsas, están excluidas de las garantías establecidas por la Ley valenciana por lo que dispone: «No será aplicable el estatuto de la persona denunciante establecido en esta ley cuando la denuncia se formule y proporcione información falsa, tergiversada u obtenida de manera ilícita».

La Ley balear también tiene como objetivo principal establecer una Oficina de Prevención y Lucha contra la Corrupción que, conforme al art. 14.3, «garantizará que cualquier persona pueda dirigirse a ella para comunicar presuntos actos de corrupción, prácticas fraudulentas o conductas ilegales que afecten a los intereses generales o la gestión de los fondos públicos».

La relación entre la Oficina balear y el informante es relevante dado que la Oficina acusará recepción del escrito o de la comunicación recibidos, deberá informar de sus derechos y obligaciones como denunciante a la persona informante, la cual podrá solicitar la confidencialidad sobre su identidad, y el personal de la Oficina estará obligado a mantenerla, excepto en el caso de que reciba un requerimiento judicial.

La debilidad de las anteriores leyes autonómicas radica en el alcance limitado de las competencias legislativas de las Comunidades Autónomas en el ámbito del Derecho penal ni del Derecho laboral. De hecho, en todas las leyes se advierte expresamente o está implícita la creación y la aplicación de un 'estatuto estatal'29.

\section{LA CLEMENCIA EN EL EJERCICIO DE LA POTESTAD SANCIONADORA PARA QUIENES DENUNCIAN ILEGALIDADES}

La denuncia de ilegalidades también puede tener consecuencias beneficiosas tanto para quien las comete como para el interés público. En este caso se trata propiamente de una delación dado que es uno de los participan en la comisión de las ilegalidades quien denuncia a los demás.

El ejemplo más significativo en el ámbito administrativo es el de la política europea de la competencia que ha terminado aplicándose en los distintos derechos nacionales y, en particular, en el Derecho español. Este es el origen, sin duda, de un cambio legislativo en España que parece anunciar el intento de generalizar esta política de clemencia en otros ámbitos.

${ }^{29}$ En el Congreso de los Diputados el Grupo Parlamentario Ciudadanos presentó en septiembre de de 2016 la Proposición de Ley Integral de Lucha contra la Corrupción y Protección de los Denunciantes. (122/000022), fue tomada en consideración en marzo de 2017 y se está tramitando en estos momentos. 


\subsection{La política de clemencia en el Derecho europeo de la competencia y su aplicación en España}

Son tres las cuestiones que tiene interés examinar: por una parte, el marco de la política de clemencia de la Comisión Europea y su control por los tribunales europeos; las cuestiones que plantea la reclamación de daños en relación con las actuaciones en materia de clemencia; y, por último, la aplicación de distintas políticas nacionales de clemencia, en particular la aplicada en España.

El Derecho europeo de la competencia se aplica tanto por la Comisión Europea como por las autoridades nacionales lo que explica una cierta complejidad jurídica que hace, por ejemplo, necesaria una atención de las empresas a la hora de solicitar clemencia, de ser posible, las primeras ante cada una de las autoridades competentes, es decir, ante la Comisión Europea y ante los 28 organismos nacionales de la competencia.

\subsubsection{La política de clemencia de la Comisión Europea y su control por los tribunales europeos}

Fue en Estados Unidos donde en 1978 se adoptó formalmente el primer programa de clemencia (antitrust leniency policy) que se revisó y adaptó en 1993, hasta convertirse en uno de los programas más efectivos y exitosos en la historia estadounidense en la detección de infracciones comerciales a gran escala ${ }^{30}$.

En la Unión Europea la Comisión adoptó en 1996 su política de clemencia a través de una Comunicación «que fija las condiciones en las que las empresas que cooperen con la Comisión en el marco de su investigación sobre un acuerdo podrán quedar exentas del pago de la multa o beneficiarse de una reducción de la multa que, en principio, habrían tenido que pagar» ${ }^{31}$. En 2002 revisó algunos aspectos de su política de clemencia introduciendo algunos aspectos como la vinculación de las reducciones de las multas a aquellas empresas que faciliten elementos de prueba que aporten un valor añadido significativo a los datos que ya obren en poder de la Comisión Europea ${ }^{32}$.

${ }^{30}$ LESLIE, Christopher R (2011): «Editorial - Antitrust Leniency Programmes», The Competition Law Review, Vol. 7/2, págs. 175-179.

${ }^{31}$ Comisión Europea (1996): Comunicación relativa a la no imposición de multas o a la reducción de su importe en los asuntos relacionados con acuerdos entre empresas (DOUE núm. C 207 de 18/07/1996, pág. 4).

${ }^{32}$ COMISIÓN EuROPEA (2002): Comunicación relativa a la dispensa del pago de las multas y la reducción de su importe en casos de cártel (DOUE núm. C 45 de 19/02/2002, pág. 3). 
En estos momentos la política de clemencia aplicable fue adoptada en $2006^{33}$. Tal como indica la Comisión Europea: «Para los consumidores y ciudadanos reviste mayor interés el descubrimiento y la prohibición de los cárteles secretos entre empresas que la imposición de multas a las empresas cuya colaboración permite a la Comisión descubrir y prohibir este tipo de prácticas» (apartado 3 ).

La política de clemencia se basa, por una parte, en una dispensa del pago de las multas a la empresa que sea la primera en aportar elementos de prueba y que, a juicio de la Comisión, le permitan realizar una inspección concreta o detectar una infracción en relación con el presunto cártel. Y, por otra parte, puede consistir en una reducción de las multas a las empresas que faciliten a la Comisión elementos de prueba de la presunta infracción que aporten un valor añadido significativo con respecto a las pruebas que ya obraban en poder de la Comisión.

La aplicación de esta política de la competencia en los últimos 10 años ha sido valorada positivamente por la Comisión Europea: «Un programa de clemencia bien diseñado es una herramienta esencial para mejorar la aplicación efectiva de las normas contra las infracciones más graves, en particular, los cárteles secretos de fijación de precios y de reparto de mercados. Sin embargo, no existe ningún requisito a nivel de la UE de tener un programa de clemencia y el ejemplar nivel de convergencia siempre puede ponerse en cuestión. Es necesario velar por garantizar los logros alcanzados en los programas de clemencia ${ }^{34}$.

El control de la política de clemencia aplicada por la Comisión Europea corresponde en instancia al Tribunal General y en casación al Tribunal de Justicia. No obstante, también por vía prejudicial el Tribunal de Justicia puede intervenir interpretando el alcance de la potestad sancionadora de las autoridades nacionales de la competencia en aplicación del Derecho antitrust europeo.

Por una parte, el Tribunal de Justicia ha puntualizado en la sentencia Pfleiderer: "los programas nacionales de clemencia son instrumentos útiles en la lucha eficaz para descubrir y detener las vulneraciones

${ }^{33}$ Comisión Europea (2006): Comunicación relativa a la dispensa del pago de las multas y la reducción de su importe en casos de cártel (DOUE núm. C 298 de 8.12.2006, pág. 17).

${ }^{34}$ Comisión Europea (2014): Diez años de aplicación de la normativa antimonopolio del Reglamento (CE) núm. 1/2003: logros y perspectivas futuras, COM (2014) 453 final, Bruselas, 9.7.2014, apartado 40. 
de las normas de competencia y sirven, por lo tanto, al objetivo de aplicación efectiva de los artículos 101 TFUE y 102 TFUE» ${ }^{35}$.

Por otra parte, el Tribunal General ha reiterado en su jurisprudencia dos ideas confirmadas en casación: en primer lugar, el programa de clemencia persigue un objetivo de instrucción, represión y disuasión de las prácticas que forman parte de las infracciones más graves del artículo 101 TFUE; y, en segundo lugar, la concesión de la dispensa condicional implica la creación de un estatuto procedimental particular en favor de la empresa que cumpla los requisitos establecidos en la Comunicación de la Comisión, que produce determinados efectos jurídicos ${ }^{36}$.

En la sentencia Deltafina el Tribunal General se refiere a las tres fases del procedimiento de clemencia: primero, la empresa que tiene intención de cooperar con la Comisión debe entrar en contacto con ella y proporcionarle elementos de prueba en relación con un presunto cártel que afecte a la competencia en la Unión (solicitud de dispensa); a continuación, la Comisión valora los elementos de prueba aportados en apoyo de dicha solicitud a fin de comprobar que la empresa cumple los requisitos establecidos y si es la primera le concederá por escrito la dispensa condicional del pago de las multas (dispensa condicional); y, finalmente, la Comisión adopta la decisión final y concede o no la dispensa del pago de las multas (dispensa definitiva) (apartados 111 a 118).

4.1.2 La política de clemencia y la reparación de los daños causados por las prácticas antitrust: jurisprudencia Pfleiderer

La violación del Derecho de la competencia tiene consecuencias públicas, que determinan, en particular, la intervención del control de las administraciones, sea la Comisión Europea sean las autoridades nacionales de la competencia, aplicando sus poderes sancionadores. También puede tener efectos privados que se traducen en la reclamación de daños causados a las empresas. De este modo se puede producir una interacción, no siempre pacífica, entre la vía pública, donde se

35 TJUE (Gran Sala), sentencia, de 14 de junio de 2011, Pfleiderer AG, C-360/09, EU: C:2011:389, apartado 25.

${ }^{36}$ TGUE, sentencia de 6 de octubre de 2015, Corporación Empresarial de Materiales de Construcción, S. A. (anteriormente Uralita), T-250/12, EU: T:2015:749, apartados 91 y 93; TGUE, sentencia de 9 de septiembre de 2011, Deltafina / Comisión, T-12/06, EU: T:2011:441, apartados 107 y 108. 
aplica la política de clemencia, y la vía privada, que pretende la reparación de los daños causados.

Así se puso de manifiesto primero en la jurisprudencia del Tribunal de Justicia y luego en la legislación europea, en particular la Directiva 2014/104/UE relativa a las acciones por daños por infracciones del Derecho de la competencia ${ }^{37}$.

En la sentencia Pfleiderer el Tribunal de Justicia se refiere a la protección de los datos personales de quienes se hayan acogido a un programa de clemencia. El litigio enfrentaba a la empresa Pfleiderer con la autoridad alemana de la competencia y se centraba en el derecho de acceso al expediente sancionador seguido contra otras tres empresas competidoras que habían sido sancionadas por vulnerar el Derecho de la competencia. En su origen el Bundeskartellamt impuso multas por un total de 72 millones de euros a tres fabricantes europeos de papel decorativo y a cinco personas físicas personalmente responsables, por la celebración de acuerdos sobre precios y de limitación de capacidades de producción. Dado que Pfleiderer había celebrado contratos con algunas de las empresas sancionadas tenía interés en preparar el ejercicio de acciones civiles por daños, por lo que reclamó a la autoridad alemana el acceso al expediente sancionador. Sin embargo, el Bundeskartellamt solo facilitó parte de la documentación y omitió secretos comerciales y otros datos, por lo que Pfleiderer recurrió al Tribunal de Bonn que acudió por vía prejudicial al Tribunal de Justicia.

El Tribunal de Justicia subraya la importancia de los programas de clemencia y de la aplicación privada del Derecho de la competencia: «los programas nacionales de clemencia son instrumentos útiles en la lucha eficaz para descubrir y detener las vulneraciones de las normas de competencia y sirven, por lo tanto, al objetivo de aplicación efectiva de los artículos 101 TFUE y 102 TFUE» (apartado 25). Pero, a continuación, el Tribunal insiste en lo decisiva que es la aplicación privada del Derecho de la competencia en la medida en que «las acciones que reclaman indemnizaciones por daños y perjuicios ante los órganos jurisdiccionales nacionales pueden contribuir sustancialmente al mantenimiento de una competencia efectiva en la Unión Europea» (apartado 29).

${ }^{37}$ Directiva 2014/104/UE del Parlamento Europeo y del Consejo, de 26 de noviembre de 2014, relativa a determinadas normas por las que se rigen las acciones por daños en virtud del Derecho nacional, por infracciones del Derecho de la competencia de los Estados miembros y de la Unión Europea (DOUE núm. L 349 de 5.12.2014, pág. 1). 
Por tanto y dada la utilidad de los programas de clemencia y las acciones por daños, el Tribunal de Justicia encomienda a los jueces nacionales la ponderación, caso por caso, en el ámbito del Derecho nacional y tomando en consideración todos los datos pertinentes (apartado 30).

En la sentencia Donau Chemie el Tribunal de Justicia precisa el alcance del derecho de acceso a documentos producidos en un procedimiento de clemencia, en los términos que había establecido el Tribunal de Justicia en la sentencia Pfleiderer ${ }^{38}$. Sobre este particular, la matización que introduce el Tribunal de Justicia respecto de la legislación austriaca determina que es contraria al derecho de la Unión si el acceso a los documentos que figuran en el expediente sancionador, incluidos los documentos comunicados en un programa de clemencia, está supeditado únicamente al consentimiento de todas las partes en dicho procedimiento, y no permite que los jueces puedan ponderar los intereses en conflicto (apartado 49).

En fin, en la sentencia Kone AG y otros / ÖBB-Infrastruktur AG, refiriéndose a la reclamación de una empresa austriaca afectada indirectamente por el cártel de los ascensores que había sido multado previamente por la Comisión Europea, el Tribunal de Justicia puntualiza: «(un) programa de clemencia no puede privar a los individuos del derecho a obtener una indemnización, ante los órganos jurisdiccionales nacionales, del daño sufrido a causa de una infracción del artículo 101 TFUE» (apartado 36) $)^{39}$.

En la Directiva 2014/104/UE se explica la relación entre la política de clemencia y las acciones por daños en materia de la competencia. Así, en el preámbulo de la Directiva se aborda esta espinosa cuestión en los siguientes términos:

Las empresas podrían verse disuadidas de cooperar con las autoridades de la competencia en el marco de programas de clemencia y procedimientos de transacción, si se exhibieran las declaraciones autoincriminatorias, como las declaraciones en el marco de un programa de clemencia y las solicitudes de transacción, que se presentan solo a efectos de cooperar con las autoridades de la competencia. Esa exhibición entrañaría el riesgo de exponer a las empresas cooperantes o a su personal directivo a una responsabilidad civil o penal en peores condiciones

38 TJUE, sentencia de 6 de junio de 2013, Bundeswettbewerbsbehörde / Donau Chemie AG y otros, C-536/11, EU: C:2013:366 (acceso a documentos objeto de un procedimiento de clemencia).

${ }^{39}$ TJUE, sentencia de 5 de junio de 2014, Kone AG y otros / ÖBB-Infrastruktur AG, C-557/12, EU: C:2014:1317 (derecho de indemnización del daño resultante del efecto paraguas y producido por una tercera empresa). 
que las de los coinfractores que no cooperan con las autoridades de la competencia. Para garantizar la buena disposición continuada de las empresas para acudir voluntariamente a las autoridades de la competencia y presentar declaraciones en el marco de un programa de clemencia o solicitudes de transacción, esos documentos deben quedar excluidos de la exhibición de pruebas.

En sintonía con estos propósitos, el art. 6.6 de la Directiva sobre daños dispone: «Los Estados miembros velarán por que, a efectos de las acciones por daños, los órganos jurisdiccionales nacionales no puedan en ningún momento ordenar a una parte o a un tercero la exhibición de cualquiera de las siguientes categorías de pruebas: a) las declaraciones en el marco de un programa de clemencia».

En 2015 se introduce una modificación en la Comunicación de 2006 que aplica la jurisprudencia del Tribunal de Justicia en relación con la posible interferencia entre los programas de clemencia y las acciones por daños por lo que se prevé: «la Comisión no transmitirá en ningún momento a los órganos jurisdiccionales nacionales declaraciones de clemencia formuladas por empresas para su uso en las demandas por daños y perjuicios por infracciones de las disposiciones del Tratado ${ }^{40}$.

Con el fin de que la eficacia de los programas de clemencia no se vea afectada por los procedimientos de reclamación de daños, la propia Comisión Europea ha establecido unas reglas de utilización de la información obtenida en un procedimiento judicial o administrativo para la aplicación de los artículos 101 y 102 del Tratado ${ }^{41}$.

\subsubsection{La política de clemencia de las autoridades administrativas españolas de la competencia}

$\mathrm{Al}$ ampliarse de una manera muy considerable la Unión Europea, desde el primero de mayo de 2004, la Comisión se ocupa únicamente de algunos aspectos esenciales del control administrativo y sancionador, convirtiéndose las Autoridades Nacionales de la Competencia (ANC) en los aplicadores ordinarios del Derecho europeo de la competencia.

${ }^{40}$ Comisión Europea (2015): Modificación de la Comunicación de la Comisión relativa a la dispensa del pago de las multas y la reducción de su importe en casos de cártel (DOUE núm. 256, 5.8.2015, pág. 1, apartado 35bis).

${ }^{41}$ Reglamento (UE) 2015/1348 de la Comisión, de 3 de agosto de 2015, por el que se modifica el Reglamento (CE) núm. 773/2004 relativo al desarrollo de los procedimientos de la Comisión con arreglo a los artículos 81 y 82 del Tratado CE (DOUE núm. 208, de 5 de agosto de 2015, pág. 3). 
En la sentencia DHL Express el Tribunal de Justicia, a requerimiento del Consejo de Estado en su calidad de Tribunal Supremo administrativo italiano, tuvo que interpretar el Derecho de la Unión sobre la política de clemencia para resolver un caso relativo a un cártel secreto en el sector de los transportes en el que la primera empresa en presentar una solicitud de dispensa, pero solo ante la Comisión Europea, fue DHL; en cambio, ante la Autoridad Italiana de la Competencia la primera en denunciarlo fue Schenker ${ }^{42}$. La cuestión se refería al régimen aplicable tanto a la política de clemencia de la Comisión Europea como a las políticas de clemencia de las autoridades nacionales.

Ahora bien, en el caso de los programas de clemencia nacionales, el Tribunal de Justicia señaló en la sentencia DHL Express que ni el Tratado de Funcionamiento de la Unión Europea ni el Reglamento 1/2003 sobre la aplicación del Derecho europeo de la competencia establecen normas comunes de clemencia. Por tanto, a falta de un sistema centralizado, a nivel de la Unión, de recepción y examen de las solicitudes de clemencia relativas a infracciones del artículo 101 TFUE, la tramitación de tales solicitudes dirigidas a una autoridad nacional de competencia se determina con arreglo a su propio Derecho nacional (apartado 35).

Y aun cuando la Red Europea de la Competencia, constituida por la Comisión y las Autoridades Nacionales de la Competencia para crear y mantener una cultura común de competencia en Europa, adoptase un programa modelo sobre clemencia en 2006, este no tiene efectos imperativos para los órganos jurisdiccionales de los Estados miembros (apartado 53).

No obstante y a pesar de esta autonomía de los distintos sistemas nacionales de clemencia, en realidad se ha producido una clara convergencia, como demuestra, sin lugar a dudas, el caso español. En efecto, la Ley española de defensa de la competencia de 2007 es la que permite la aplicación por la autoridad española de la competencia de un régimen de clemencia similar al europeo ${ }^{43}$. En su preámbulo la Ley española de defensa de la competencia explica que «se introduce un procedimiento de clemencia, similar al vigente en el ámbito comunitario, en virtud del cual se exonerará del pago de la multa a las empresas que, habiendo formado parte de un cártel, denuncien su existencia y aporten pruebas sustantivas para la investigación, siempre y

${ }^{42}$ TJUE, sentencia de 20 de enero de 2016, DHL Express (Italy) y DHL Global Forwarding (Italy), C-428/14, EU: C:2016:27.

${ }^{43}$ Ley 15/2007, de 3 de julio, de Defensa de la Competencia (BOE núm. 159, de 4 de julio de 2007). 
cuando cesen en su conducta infractora y no hayan sido los instigadores del resto de miembros del acuerdo prohibido».

Los artículos 65 y 66 de la Ley española se refieren a los supuestos de exención del pago y de reducción del importe de la multa.

La exención del pago de la multa exige que la empresa sea la primera en aportar elementos de prueba que, a juicio de la Comisión Nacional de la Competencia, le permitan ordenar el desarrollo de una inspección o que le permitan comprobar una infracción en relación con un cártel, siempre y cuando, en el momento de aportarse los elementos, la Comisión Nacional de la Competencia no disponga de elementos de prueba suficiente.

Asimismo, la empresa debe cooperar plena, continua y diligentemente; debe poner fin a su participación en la presunta infracción; y no puede haber destruido elementos de prueba relacionados con la solicitud de exención ni haber revelado, directa o indirectamente, a terceros distintos de la Comisión Europea o de otras Autoridades de Competencia, su intención de presentar esta solicitud o su contenido; ni haber adoptado medidas para obligar a otras empresas a participar en la infracción.

En cambio, por lo que se refiere a la reducción del importe de la multa procede cuando las empresas o personas físicas que, sin reunir los requisitos anteriores, faciliten elementos de prueba de la presunta infracción que aporten un valor añadido significativo con respecto a aquéllos de los que ya disponga la Comisión Nacional de la Competencia. El nivel de reducción se fija entre el 30 y $50 \%$ para la primera denunciante; entre el 20 y el $30 \%$ para la segunda; y en el caso de las sucesivas podrán beneficiarse de una reducción de hasta el $20 \%$ del importe de la multa.

El Reglamento de Defensa de la Competencia desarrolla en sus artículos 46 a 53 todas las cuestiones relativas a los procedimientos de exención y de reducción de las multas ${ }^{44}$. También se establecen en el artículo 53 del Reglamento mecanismos de coordinación con los órganos competentes de las Comunidades Autónomas en los procedimientos de exención del importe de la multa. De manera complementaria la propia Autoridad Española de la Competencia ha adoptado una Comunicación interpretativa ${ }^{45}$.

\footnotetext{
${ }^{44}$ Real Decreto 261/2008, de 22 de febrero, por el que se aprueba el Reglamento de Defensa de la Competencia (BOE núm. 50, de 27 de febrero de 2008).

${ }^{45}$ Comisión Nacional de la Competencia (2013): Comunicación de 19 de junio de 2013, sobre el Programa de Clemencia (BOE núm. 196, 16 de agosto de 2013).
} 


\subsection{La generalización de la política de clemencia en el Derecho administrativo sancionador español}

Desde el 2 de octubre de 2016 la nueva Ley del procedimiento administrativo común ha introducido una regulación específica, con carácter de norma estatal básica, por la que se establecen las bases de una política de clemencia en el Derecho administrativo sancionador español ${ }^{46}$.

Esta nueva regulación ya se recogía en el Anteproyecto de ley sometido a información pública el 16 de enero de 2015 (artículo 89.3) y fue objeto de atención por el propio Consejo de Estado. Este se mostraba particularmente cauto con esta generalización del procedimiento de clemencia y señalaba:

Sin desconocer la utilidad del procedimiento de clemencia en muchos de los ámbitos de actuación de las Administraciones Públicas, es lo cierto que su regulación como mecanismo de aplicación genérica dentro del procedimiento administrativo común puede colisionar con lo dispuesto en las leyes sectoriales en las que se regula tal procedimiento (así, en la legislación sobre protección de datos, en la de defensa de la competencia o en el ámbito tributario). Se trata de un mecanismo eficaz para incentivar la denuncia de infracciones y, con ello, facilitar su detección y sanción. Sin embargo, su extensión, de forma global y generalizada, a todos los procedimientos sancionadores, impide atender a las peculiaridades que por razón de la materia puedan existir en cada caso, lo que hace preferible mantener la regulación de este procedimiento en la legislación sectorial. Se recomienda por ello valorar la conveniencia de introducir una regla de este tipo en la ley reguladora del procedimiento administrativo común ${ }^{47}$.

Ahora bien, la versión inicial del Gobierno español se mantuvo y se aprobó con apenas modificaciones en lo que es el vigente art. 62.4 de la Ley 39/2015.

En primer lugar, se establece la exención de la multa o de la sanción al primero en aportar elementos de prueba que permitan iniciar el procedimiento o comprobar la infracción. El requisito fundamental es que no se disponga de elementos suficientes para ordenar la multa o la sanción no pecuniaria y se repare el perjuicio causado.

${ }^{46}$ Ley 39/2015, de 1 de octubre, del Procedimiento Administrativo Común de las Administraciones Públicas (BOE núm. 236, de 02/10/2015).

${ }^{47}$ Consejo de Estado (Comisión Permanente) (2015): Dictamen, de 29 de abril de 2015, sobre el Anteproyecto de Ley del Procedimiento Administrativo Común de las Administraciones Públicas, apartado 18. 
En segundo lugar, se prevé la reducción del importe de la multa o de la sanción cuando el denunciante facilite elementos de prueba que aporten un valor añadido significativo respecto de aquellos de los que se disponga.

Para ambos supuestos se añade una doble exigencia: que el denunciante cese en la participación de la infracción y que no haya destruido elementos de prueba relacionados con el objeto de la denuncia.

A diferencia de la cautela mostrada por el Consejo de Estado, debe darse la bienvenida a estas reglas estatales básicas que pueden utilizarse en otras legislaciones sectoriales y que sirven de orientación y guía en la legislación sancionadora autonómica.

\section{LOS INCENTIVOS ECONÓMICOS PARA DENUNCIAR ILEGALIDADES}

El 6 de enero de 2017 la Oficina estadounidense del mercado de valores (SEC) anunciaba en Washington que había recompensado con más de cinco millones y medio de dólares a un empleado de una compañía que había sido investigada y castigada por ilegalidades en el ámbito financiero. En su comunicado oficial la SEC recordaba que desde 2012 ya había recompensado con más de 142 millones de dólares a 38 denunciantes y que las recompensas van desde el 10 al $30 \%$ del dinero recaudado siempre que la sanción supere el millón de dólares ${ }^{48}$.

La protección y el incentivo de los confidentes en los mercados financieros han sido regulados también por el Derecho de la Unión a través del Reglamento (UE) n ${ }^{\circ} 596 / 2014$ sobre el abuso de mercado que se refiere expresamente al establecimiento de incentivos económicos para fomentar el whistle-blowing.

En el apartado 74 del preámbulo del Reglamento se explica: «Los Estados miembros deben poder prever incentivos financieros para las personas que ofrecen información relevante sobre posibles infracciones del presente Reglamento. Sin embargo, han de tener derecho a tales incentivos únicamente los confidentes que saquen a la luz nueva información que no estuviera ya sujeta al deber de notificación y que dé lugar a la imposición de sanciones por infracción del presente Reglamento».

${ }^{48}$ U. S. Securities and Exchange Commission (2017): «SEC Awards \$5.5 Million to Whistleblower», disponible en https://www.sec.gov/news/pressrelease/2017-1.html (consulta: 07/01/2017). 
El artículo 32, sobre comunicación de las infracciones, faculta en su apartado 4 a los Estados miembros para «prever, de acuerdo con la normativa nacional aplicable, la concesión de incentivos económicos a las personas que ofrezcan información relevante sobre posibles infracciones del presente Reglamento, siempre que esas personas no estén sometidas a otras obligaciones legales o contractuales previas de facilitar tal información, que esta sea nueva y que dé lugar a la imposición de una sanción administrativa o penal, o a la adopción de otra medida administrativa por infracción del presente Reglamento».

La futura legislación española de incorporación de tales previsiones deberá decidir si hace uso de esta facultad para establecer los mecanismos apropiados.

También en el ámbito del Derecho de la Unión debería analizarse si tales incentivos económicos pueden aplicarse, mutatis mutandis, en la protección de los intereses financieros de la Unión.

\section{CONCLUSIÓN}

Cuando una acción como el whistle-blowing plantea, de entrada, tantos problemas terminológicos parece revelar profundas diferencias culturales y políticas que tienen reflejo en una regulación jurídica reciente, fragmentaria y elusiva. De hecho, en español no hay consenso para traducir el término inglés y ni siquiera el Diccionario del Español Jurídico de 2016 recoge referencia directa alguna a esta realidad que ahora mismo está abordando el legislador y que ya ha tenido que discutirse en los tribunales.

En la aplicación de determinadas políticas públicas se ha comprendido la virtualidad que puede llegar a tener la explotación de las más nobles motivaciones ciudadanas pero también del interés propio o incluso del mero incentivo económico. En contrapartida, las autoridades públicas deben proteger al ciudadano corriente y leal que, sin embargo, ya no tiene vocación de héroe ni aspira al martirio; y también los poderes públicos deben hacer gala, al estilo del tradicional príncipe clemente, de su benevolencia eximiendo o reduciendo la sanción administrativa que merecerían quienes contribuyen a delatar a los participantes en infracciones graves de las normas jurídicas.

Aunque no puede descartarse el riesgo de establecer una sociedad de la sospecha y de la delación, como llegó a construirse en el cercano siglo $\mathrm{XX}$, en las dictaduras fascistas y comunistas pero también en los regímenes democráticos, en una sociedad abierta debe conjurarse 
esta posibilidad con limitaciones y garantías en los distintos ámbitos afectados: la libre competencia, los mercados financieros, etc. En este sentido, la recepción que se ha hecho en Europa de la práctica del whistle-blowing puede considerarse apropiada. El soft law producido en la OCDE, en el Consejo de Europa y en la Unión Europea ha ido calando paulatinamente en las distintas legislaciones europeas y nacionales.

En España la atención a estas cuestiones ha sido, paradójicamente y en un contexto de corrupción pública, muy escasa. No pueden descartarse razones históricas y culturales que expliquen este desinterés. Sin embargo, a través de la recepción del Derecho de la Unión, en particular en materia de libre competencia y de la protección de los mercados financieros, y mediante las recientes legislaciones autonómicas que pretenden crear un estatuto del denunciante o del informante, parece que todo puede cambiar en el panorama jurídico español. Así, en el caso de que se pretenda introducir recompensas por denuncias en el ámbito de los mercados financieros deberá discutirse en el ágora pública la conveniencia y la utilidad de estos incentivos, a primera vista tan extraños en una sociedad como la europea o la española y que tantos recuerdos trae del Lejano Oeste de la Biblia y el revólver.

En suma, la regulación que se establezca en España y en Europa debe ponderar con gran prudencia el tipo de sociedad que queremos construir: una sociedad abierta en la que los ciudadanos participen y consideren como propia la gestión pública o una sociedad enferma en la que lo único que cuenta es el sálvese quien pueda. De este modo, el príncipe soberano del que todos formamos parte en una sociedad democrática tendrá que distinguir al ciudadano que denuncia ilegalidades que afectan al bien común del más despreciable soplón. 
